\title{
Molecular structures of $\mathrm{M}\left(\mathrm{Bu}^{t}\right)_{3}(\mathrm{M}=\mathrm{Al}, \mathrm{Ga}, \mathrm{In})$ using gas-phase electron diffraction and $a b$ initio calculations: experimental and computational evidence for charge-transfer processes leading to photodissociation $\dagger$
}

\author{
Andrea Keys, ${ }^{a}$ Paul T. Brain, ${ }^{b}$ Carole A. Morrison, ${ }^{b}$ Rhonda L. Callender, ${ }^{a}$ Bruce A. Smart, ${ }^{b}$ Derek A. Wann, ${ }^{b}$ \\ Heather E. Robertson, ${ }^{b}$ David W. H. Rankin ${ }^{* b}$ and Andrew R. Barron*a
}

Received 13th September 2007, Accepted 9th November 2007

First published as an Advance Article on the web 12th December 2007

DOI: 10.1039/b714168h

The gas-phase structures of $\mathrm{Al}\left(\mathrm{Bu}^{t}\right)_{3}$ and $\mathrm{Ga}\left(\mathrm{Bu}^{t}\right)_{3}$ have been investigated by electron diffraction and are shown to consist of monomeric units with very slightly pyramidal geometries. Salient structural parameters $\left(r_{\mathrm{h} 1}\right)$ include $r_{\mathrm{Al}-\mathrm{C}}=2.008(2) \AA$ and $r_{\mathrm{Ga}-\mathrm{C}}=2.032(2) \AA$. For both compounds the ligand orientations and geometries are controlled by interligand interactions. The structures of $\mathrm{M}\left(\mathrm{Bu}^{t}\right)_{3}$ $(\mathrm{M}=\mathrm{Al}, \mathrm{Ga}, \mathrm{In})$ have been calculated $a b$ initio and those for the aluminium and gallium derivatives are in good agreement with the electron-diffraction structures. Comparison of the $a b$ initio calculated structure of $\mathrm{In}\left(\mathrm{Bu}^{t}\right)_{3}$ with those of $\mathrm{Al}\left(\mathrm{Bu}^{t}\right)_{3}$ and $\mathrm{Ga}\left(\mathrm{Bu}^{t}\right)_{3}$ suggests that the significantly different photochemistry exhibited by the former does not result from structural factors. In fact the compounds undergo a charge-transfer process in the UV region, with the wavelength required calculated to be slightly longer for the indium compound than for the other two.

\section{Introduction}

The tert-butyl derivatives of the Group 13 metals aluminium, gallium and indium are versatile reagents in chemical synthesis, ${ }^{1}$ with the rationale for their use based on a number of inherent properties. The steric bulk of the tert-butyl groups means that derivatives of the molecules $\mathrm{M}\left(\mathrm{Bu}^{t}\right)_{3}(\mathrm{M}=\mathrm{Al}, \mathrm{Ga}, \mathrm{In})$ can be isolated, ${ }^{2}$ while analogues with smaller alkyl groups are unstable. ${ }^{3}$ However, the steric bulk of the tert-butyl groups is not so much larger than other alkyl groups that tert-butyl analogues of known alkyl compounds cannot be synthesised. ${ }^{4}$ Another useful property inherent in these compounds is a high activation barrier to alkyl exchange; this allows species to be isolated that would be fluxional (or in exchange equilibria) if the ligands were primary or secondary alkyl groups rather than tert-butyl. Oligomer formation is known to be limited, thus allowing relatively volatile derivatives to be prepared, ${ }^{5}$ whilst retaining the useful property that the majority of tert-butyl compounds of the Group 13 metals are solids and therefore amenable to characterisation by X-ray crystallography ${ }^{6}$ without significant disorder of the substituents. ${ }^{7}$

Until recently, despite the fact that the crystal structures of over 160 tert-butyl derivatives of aluminium, gallium and indium had been determined, ${ }^{8}$ the parent tri-tert-butyl derivatives, $\mathrm{Al}\left(\mathrm{Bu}^{t}\right)_{3}, \mathbf{1}$, $\mathrm{Ga}\left(\mathrm{Bu}^{t}\right)_{3}, \mathbf{2}$, and $\mathrm{In}\left(\mathrm{Bu}^{t}\right)_{3}, \mathbf{3}$, had not been characterised by X-ray diffraction. However, while this manuscript was in preparation two essentially identical structures were reported for each of $1,9,10$ $2^{10,11}$ and $\mathbf{3}^{10,12}$ as well as for $\mathrm{B}\left(\mathrm{Bu}^{t}\right)_{3}{ }^{10}$ This has allowed us to make

${ }^{a}$ Department of Chemistry, Rice University, Houston, Texas, 77005, USA. E-mail:arb@rice.edu

${ }^{b}$ School of Chemistry, University of Edinburgh, West Mains Road, Edinburgh, UK EH9 3JJ.E-mail: d.w.h.rankin@ed.ac.uk

$\dagger$ Electronic supplementary information (ESI) available: Additional experimental details (Tables S1-S12). See DOI: 10.1039/b714168h comparisons between the structures of $\mathbf{1}$ and $\mathbf{2}$ in the gaseous and crystalline phases.

To investigate anomalies relating to stability within the homologous series of tri-tert-butyl compounds of the Group 13 metals, we have performed a combined gas-phase electron-diffraction (GED) and $a b$ initio study of the structures of $\mathrm{M}\left(\mathrm{Bu}^{t}\right)_{3}(\mathrm{M}=\mathrm{Al}, \mathrm{Ga}, \mathrm{In})$. First, the results from ab initio calculation for 1-3 are presented. These are followed by structures determined by GED for $\mathbf{1}$ and 2. Finally, the results are compared and we discuss attempts to explain the aforementioned differences in molecular stability.

\section{Experimental}

Synthesis

1 and $\mathbf{2}$ were prepared according to previously published procedures, ${ }^{13,14}$ and purified by recrystallisation. Measurements of their ${ }^{1} \mathrm{H}$ and ${ }^{13} \mathrm{C}$ NMR spectra confirmed the samples were pure, to within the sensitivity of the spectrometer. ${ }^{13,14}$

\section{Gas-phase electron diffraction}

Electron-diffraction patterns for $\mathbf{1}$ and $\mathbf{2}$ were recorded photographically on Kodak Electron Image plates using the Edinburgh GED apparatus, ${ }^{15}$ operating at an accelerating voltage of approximately $40 \mathrm{kV}$. Data were collected at two nozzle-tofilm distances, viz. $256.9 \mathrm{~mm}$ [for 1 and 2] and $93.9 \mathrm{~mm}$ [for 1] or $89.6 \mathrm{~mm}$ [for 2]. The patterns were converted to digital format using a PDS microdensitometer at the Royal Greenwich Observatory, Cambridge, employing a $200 \mu \mathrm{m}$ pixel size. ${ }^{16}$ The temperatures required for the GED experiments were dependent on both the nature of the compound and the nozzle-to-film distance and are given in the ESI, Table S1. $\uparrow$ The scattering data were analysed using data-reduction and least-squares programs described elsewhere, ${ }^{17}$ employing the electron scattering factors 
of Ross et al. ${ }^{18}$ The weighting points for the off-diagonal weight matrices used in the least-squares processes, together with other experimental parameters, are also listed in Table S1.†

\section{Ab initio calculations}

All molecular-orbital calculations were carried out using the resources of the National Service for Computational Chemistry Software (NSCCS) ${ }^{19}$ with the Gaussian 03 suite of programs. ${ }^{20}$ For the initial geometry optimisations of 1-3 at the RHF level, 3$21 \mathrm{G}^{* 21}$ and $6-31 \mathrm{G}^{* 22}$ basis sets were employed, with the molecules constrained to $C_{3 \mathrm{~h}}, C_{3 \mathrm{v}}$ and $C_{3}$ symmetries. Frequency calculations indicated that the only structures representing minima on the respective potential-energy surfaces were those with $C_{3}$ symmetry. Geometry optimisations were performed subsequently in $C_{3}$ symmetry at the MP2 level of theory using 6-31G*, 6-311G*, ${ }^{23}$ and 6-311+ $\mathrm{G}^{*}$ basis sets on $\mathrm{H}, \mathrm{C}, \mathrm{Al}$ and $\mathrm{Ga}$. In the case of In, for which no standard Pople-style basis set larger than $3-21 \mathrm{G}^{*}$ is available, a basis set from Huzinaga ${ }^{24}$ was used with an additional diffuse d-polarisation function (exponent 0.10 ), contracted to $(21 \mathrm{~s}, 17 \mathrm{p}$, $11+1 \mathrm{~d}) /[15 \mathrm{~s}, 12 \mathrm{p}, 7+1 \mathrm{~d}]$. Geometry optimisations and frequency calculations at the MP2/6-311+G* were also performed for 1 and 2 in $C_{3 \mathrm{~h}}$ and $C_{3 \mathrm{v}}$ symmetries. These calculations were carried out to ensure that those structures were not potential minima at this level and to allow the energy differences between them and the $C_{3}$ structures to be deduced.

The MP2 frozen-core (FC) approximation divides electrons into two categories, core and valence, with only the valence electrons considered in the electron-correlation treatment. The default FC approximation satisfactorily placed the electrons of carbon and aluminium as core or valence, but unsatisfactorily placed the ten gallium 3d (and indium 4d) electrons in the core region; consideration of the orbital energies clearly shows that these outercore orbitals lie closer in energy to the $4 \mathrm{~s}$ and $4 \mathrm{p}$ (or $5 \mathrm{~s}$ and $5 \mathrm{p}$ ) valence orbitals than to the remaining inner-core orbitals. The MP2(full) method was used for calculating the structures of 2 and $\mathbf{3}$, thereby including all electrons in the electron-correlation treatment.

For 1 and 2, frequency calculations were performed at the MP2/6-311+G* level to obtain harmonic force fields. These were then used with the program SHRINK ${ }^{25}$ to generate amplitudes of vibration $\left(u_{\mathrm{h} 1}\right)$, used as starting values in the GED refinements, and perpendicular distance corrections $\left(k_{\mathrm{h} 1}\right)$, used to counter the effects of vibrational averaging.

A complete active space multiconfiguration SCF (CASSCF) calculation $^{26}$ allows accurate energies to be computed for ground and excited-state configurations. The CASSCF calculation is a combination of an SCF computation and a full configuration interaction (CI) calculation involving a subset of the orbitals. The orbitals involved in the CI calculation are known as the active space. Such calculations were performed for each of 1-3. First, the natural orbitals were calculated at the RHF/3-21G* level to ensure that the orbitals were correctly ordered for the CASSCF calculations. The active space was then defined, assuming that the electrons involved are taken from as many of the highest occupied molecular orbitals (HOMOs) as are needed to obtain the specified number of electrons, and that any remaining required orbitals are taken from the lowest energy virtual orbitals. For our calculations a 6-electron, 7-orbital CAS was necessary to allow the first excited state to be accessed. Calculations were performed for both the ground state and excited state and then the excitation energy was deduced.

Although not as accurate as CASSCF, time-dependent DFT calculations ${ }^{27}$ can also be used to estimate excitation energies. For each of 1-3 these energies have been estimated using the B3LYP ${ }^{28}$ functional with the LanL2DZ basis set (no pseudopotential) ${ }^{29}$ on all atoms.

\section{GED model}

Based on the ab initio calculations described above, parameterised geometric models were written for $\mathbf{1}$ and $\mathbf{2}$ describing their $C_{3}$ symmetric structures. Fig. 1 shows the atom numbering employed for the heavy-atom skeleton and Table 1 contains a summary of the independent geometrical parameters used in the models.

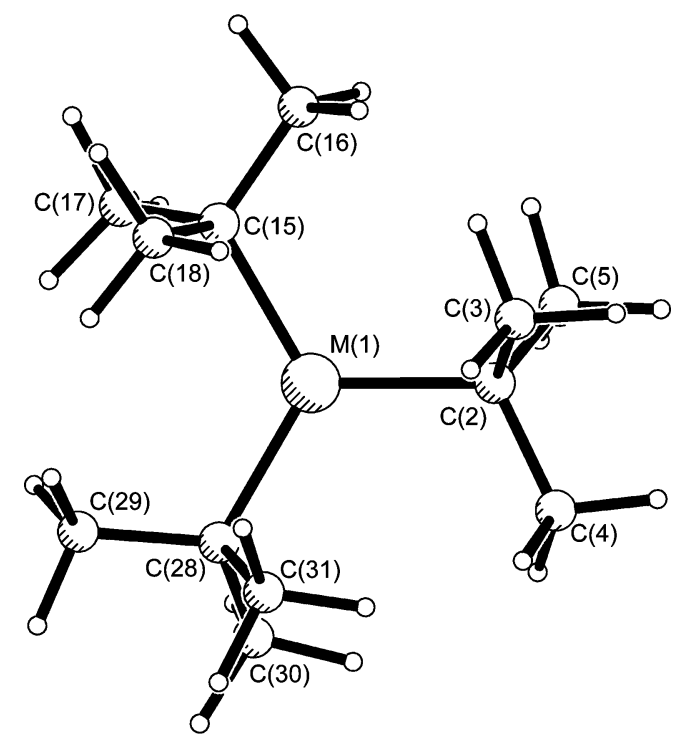

Fig. 1 General structure of $\mathrm{M}\left(\mathrm{Bu}^{t}\right)_{3}$ including heavy-atom numbering.

Calculations for both $\mathbf{1}$ and $\mathbf{2}$ showed that the range of $\mathrm{C}-\mathrm{H}$ distances was small and, therefore, a single $\mathrm{C}-\mathrm{H}$ bond length was used $\left(p_{1}\right)$. The $\mathrm{C}-\mathrm{C}$ bond lengths were represented by the average distance $\left(p_{2}\right)$, and fixed (i.e. non-refinable) differences were applied to allow for the small deviations from this mean value. The final distance used in the model was the $\mathrm{M}-\mathrm{C}$ bond length $\left(p_{3}\right)$.

It is common when writing a GED model to assume that a methyl group has $C_{3 \mathrm{v}}$ symmetry as this allows that group to be described using one $\mathrm{C}-\mathrm{H}$ distance parameter and one $\mathrm{X}-\mathrm{C}-\mathrm{H}$ angle. In this case calculations (MP2/6-311+ $\mathrm{G}^{*}$ ) showed that to a good approximation all methyl groups were identical, but that the assumption of $C_{3 v}$ symmetry was far from accurate. In each methyl group one $\mathrm{C}-\mathrm{C}-\mathrm{H}$ angle was significantly narrower than the other two (approximate $C_{\mathrm{s}}$ symmetry). For this reason two $\mathrm{C}-$ $\mathrm{C}-\mathrm{H}$ angles, included as the simple average of the values and the difference between them, were used $\left(p_{4-5}\right)$. To describe the marked asymmetry of the tert-butyl groups, the average value of the $\mathrm{M}_{-}$ $\mathrm{C}-\mathrm{C}$ angles and two related differences were used $\left(p_{6-8}\right)$ as follows:

$$
\begin{gathered}
p_{6}=[\mathrm{M}-\mathrm{C}-\mathrm{C}(4)+\mathrm{M}-\mathrm{C}-\mathrm{C}(5)+\mathrm{M}-\mathrm{C}-\mathrm{C}(3)] / 3 \\
p_{7}=\mathrm{M}-\mathrm{C}-\mathrm{C}(4)-[\mathrm{M}-\mathrm{C}-\mathrm{C}(5)+\mathrm{M}-\mathrm{C}-\mathrm{C}(3)] / 2
\end{gathered}
$$


Table 1 Geometric parameters from the GED-refined and calculated structures of $\mathrm{Al}\left(\mathrm{Bu}^{t}\right)_{3}, \mathbf{1}, \mathrm{Ga}\left(\mathrm{Bu}^{t}\right)_{3}, \mathbf{2}$, and $\operatorname{In}\left(\mathrm{Bu}^{t}\right)_{3}, \mathbf{3}^{a}$

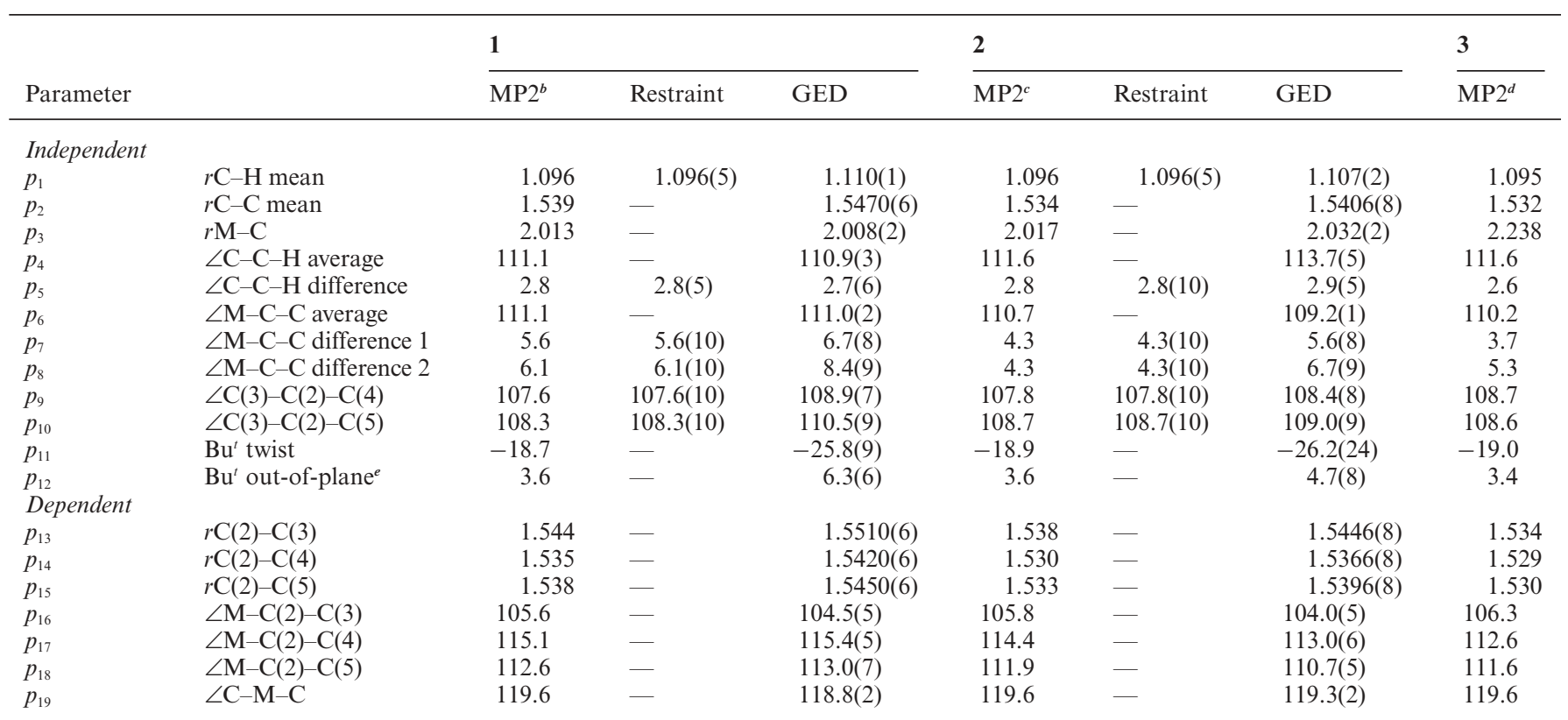

${ }^{a}$ Distances $(r)$ are in $\AA$, bond angles $(\angle)$ and dihedral angles are in ${ }^{\circ}$. See text for parameter definitions. Figures in parentheses are the estimated standard deviations of the last digits. Restraints were applied in accordance with the SARACEN method. ${ }^{30}{ }^{b} \mathrm{MP} 2(\mathrm{FC}) / 6-311+\mathrm{G}^{*} .{ }^{c} \mathrm{MP} 2(\mathrm{full}) / 6-311+\mathrm{G}^{*}$. ${ }^{d} \mathrm{MP} 2$ (full)/6-311+G*/Huzinaga. ${ }^{e}$ Defined as the angle between each $\mathrm{M}-\mathrm{C}$ bond and the plane perpendicular to the $C_{3}$ axis.

$$
\begin{gathered}
p_{8}=\mathrm{M}-\mathrm{C}-\mathrm{C}(5)-\mathrm{M}-\mathrm{C}-\mathrm{C}(3) \\
\mathrm{M}-\mathrm{C}-\mathrm{C}(4)=p_{6}+\left(2 / 3 \times p_{7}\right) \\
\mathrm{M}-\mathrm{C}-\mathrm{C}(5)=p_{6}-\left(1 / 3 \times p_{7}\right)+\left(1 / 2 \times p_{8}\right) \\
\mathrm{M}-\mathrm{C}-\mathrm{C}(3)=p_{6}-\left(1 / 3 \times p_{7}\right)-\left(1 / 2 \times p_{8}\right)
\end{gathered}
$$

Two $\mathrm{C}_{\mathrm{Me}}-\mathrm{C}-\mathrm{C}_{\mathrm{Me}}$ angles $\left(p_{9-10}\right)$ were also used.

The final two parameters required to describe the geometries of 1 and $\mathbf{2}$ were a dihedral angle to allow the tert-butyl groups to rotate $\left(p_{11}\right)$ and an angle $\left(p_{12}\right)$ to allow the tert-butyl groups to move out of the $\mathrm{MC}_{3}$ plane so that the molecule becomes pyramidal rather than planar. The formal definitions of $p_{11}$ and $p_{12}$ require the use of a dummy atom (X) equidistant from each of $\mathrm{C}(2), \mathrm{C}(15)$ and $\mathrm{C}(28)$ placed on the principal rotation axis in the direction of the base of the pyramid motif. The rotation of the tert-butyl groups (which are symmetry-equivalent) is defined using $\phi \mathrm{X}-\mathrm{M}-\mathrm{C}(2)-$ $\mathrm{C}(3)$, where a value of $0^{\circ}$ would mean that $\mathrm{X}-\mathrm{M}$ and $\mathrm{C}(2)-\mathrm{C}(3)$ eclipse one another. The out-of-plane parameter is defined as $90^{\circ}$ minus $\angle \mathrm{X}-\mathrm{M}-\mathrm{C}(2)$, where a value of $0^{\circ}$ for the parameter would signify a coplanar $\mathrm{MC}_{3}$ fragment.

\section{Results and discussion}

\section{Ab initio molecular-orbital calculations}

A graded series of calculations was performed for each of 1-3 in order to gauge the effects of basis set and electron-correlation treatment on the optimised structures. Sets of Cartesian coordinates obtained from the highest-level calculations are available in Tables S2-S4.†
Changes in molecular geometry with improvements in basis set and level of theory were small, with most changes involving the lengths of the $\mathrm{M}-\mathrm{C}$ bonds. The parameters relating to the tertbutyl groups converge rapidly, changing little upon improvement of the theoretical treatment.

As can be seen from Table 1, the experimentally observed bond lengths and angles are reproduced well by the $a b$ initio calculations. This suggests that $a b$ initio calculations at this level may be used successfully to predict structural trends in heavier Group 13 organometallic compounds, and allow comparison of the $a b$ initio calculated structure for $\operatorname{In}\left(\mathrm{Bu}^{t}\right)_{3}$ with the GED structures of $\mathrm{Al}\left(\mathrm{Bu}^{t}\right)_{3}$ and $\mathrm{Ga}\left(\mathrm{Bu}^{t}\right)_{3}$. Unless otherwise stated, discussion will be limited to experimentally determined structures for $\mathrm{Al}\left(\mathrm{Bu}^{t}\right)_{3}$ and $\mathrm{Ga}\left(\mathrm{Bu}^{t}\right)_{3}$ and the calculated structure [MP2(full)/6$311+\mathrm{G}^{*} /$ Huzinaga] for $\operatorname{In}\left(\mathrm{Bu}^{t}\right)_{3}$.

\section{GED refinement}

The experimental molecular-scattering intensity curves for $\mathbf{1}$ and 2 are shown in Fig. 2. Fourier transformation of the combined molecular-scattering intensity sets for each molecule yields the radial-distribution curves shown in Fig. 3. The refinement processes for $\mathbf{1}$ and $\mathbf{2}$ were essentially identical. Starting values for the geometric parameters were taken from geometry optimisations (MP2/6-311+G*) and amplitudes of vibrations were derived from force-field calculations at the same level using the SHRINK program. ${ }^{25}$ These parameters were subsequently refined, using flexible restraints where necessary, in accordance with the SARACEN method. ${ }^{30}$ Additionally, 13 groups of amplitudes of vibration were refined for 1 and 11 groups were refined for $\mathbf{2}$. Table 1 shows the final refined geometrical parameters, while in Tables $\mathrm{S} 5$ and $\mathrm{S} 6 \dagger$ interatomic distances are listed for $\mathbf{1}$ and $\mathbf{2}$, respectively, along with the values of the corresponding amplitudes of vibration. Elements 



Fig. 2 Experimental and difference (experimental minus theoretical) molecular-scattering intensity curves for (a) $\mathrm{Al}\left(\mathrm{Bu}^{t}\right)_{3}, \mathbf{1}$, and (b) $\mathrm{Ga}\left(\mathrm{Bu}^{t}\right)_{3}, 2$.

of the least-squares correlation matrices are given in Tables S7 and $\mathrm{S} 8 \dagger$ and sets of Cartesian coordinates from the final refined structures are in Tables S9 and S10.† The unrefined intensity data are given in Tables $\mathrm{S} 11$ and $\mathrm{S} 12 . \dagger$ The final refinements returned values of $R_{\mathrm{G}}=0.034\left(R_{\mathrm{D}}=0.034\right)$ and $R_{\mathrm{G}}=0.045\left(R_{\mathrm{D}}=0.048\right)$ for $\mathbf{1}$ and $\mathbf{2}$, respectively.

For each of the refinements, the value of the $\mathrm{Bu}^{t}$ out-of-plane bend was then fixed at $0^{\circ}$ to ascertain the effect on the $R$ factor. For $1 R_{\mathrm{G}}$ rose to 0.046 when this was done and for $2 R_{\mathrm{G}}$ rose to 0.063 . No other parameter changed significantly when this was done. Calculations had been performed on two structures where the $\mathrm{MC}_{3}$ moiety was planar $\left(C_{3 \mathrm{~h}}\right.$ and $C_{3 \mathrm{v}}$ symmetry). For both 1 and 2 both of these structures had similar energies, which were calculated (MP2/6-311+G*) to be more than $5 \mathrm{~kJ} \mathrm{~mol}^{-1}$ higher in energy than the pyramidal $C_{3}$ structure. Although the values for the out-of-plane bends are small, so too are the uncertainties associated with them. Additionally, no restraints have been applied to these parameters. This evidence leads to our confidence in the accuracy of the GED structures determined.

\section{Comparison of structures}

As might be expected, based on the steric bulk of a tert-butyl group relative to a methyl group, the $\mathrm{M}-\mathrm{C}$ distances in $\mathrm{M}\left(\mathrm{Bu}^{t}\right)_{3}[2.008(2)$ and 2.032(2) $\AA$ for $\mathrm{M}=\mathrm{Al}$ and $\mathrm{Ga}$, respectively] are longer than those found for their methyl analogues [1.957(3) $\AA$ in $\mathrm{AlMe}_{3},{ }^{31}$ 1.967(2) $\AA$ in $\mathrm{GaMe}_{3}{ }^{32}$ ] and for other less sterically demanding alkyl substituents, e.g. $1.982(6)$ to $1.997(6) \AA$ in $\mathrm{Al}\left(\mathrm{CH}_{2} \mathrm{Ph}\right)_{3} \cdot{ }^{33}$ This
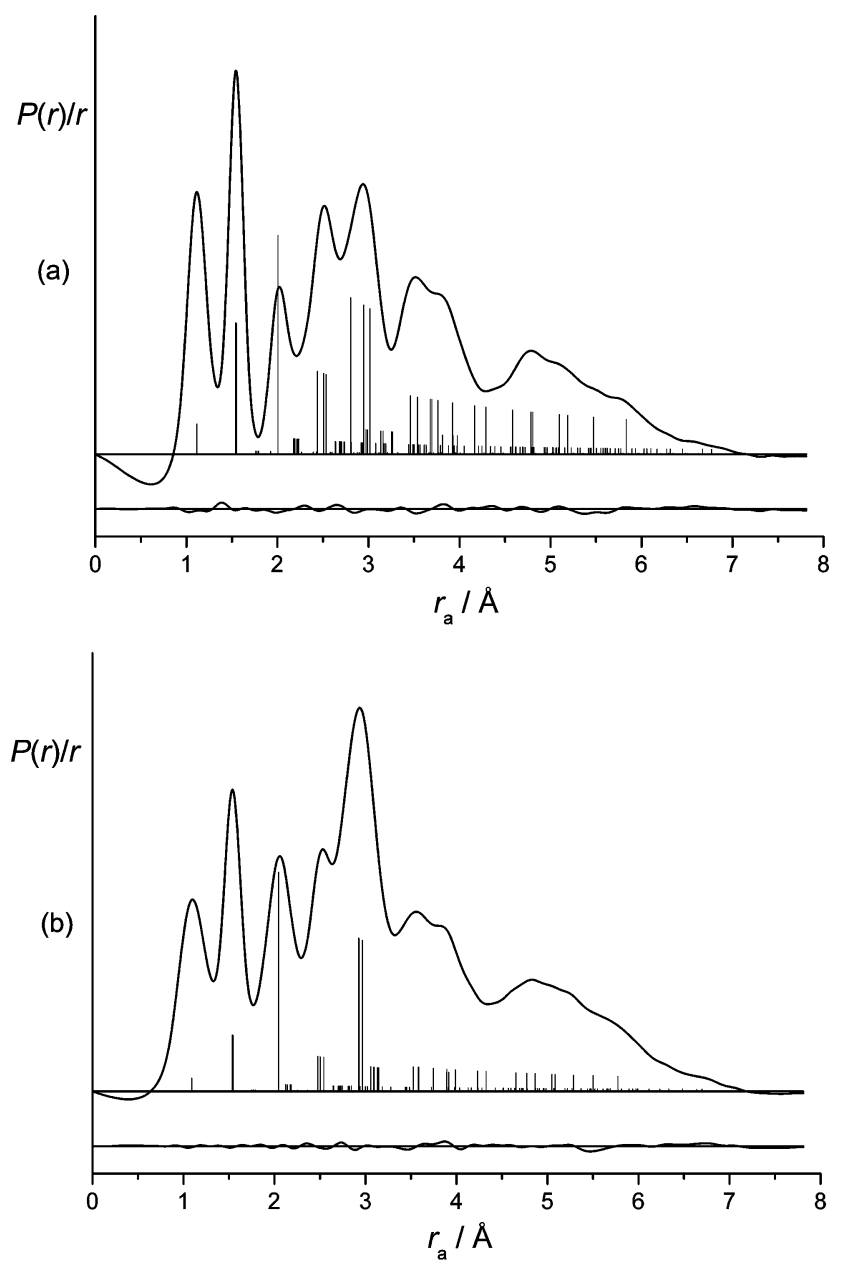

Fig. 3 Experimental radial-distribution curves and difference curves (theoretical minus experimental) for the refinements of (a) $\mathrm{Al}\left(\mathrm{Bu}^{t}\right)_{3}, \mathbf{1}$, and (b) $\mathrm{Ga}\left(\mathrm{Bu}^{t}\right)_{3}, 2$. Before Fourier inversion the data were multiplied by $s \exp \left(-0.00002 s^{2}\right) /\left(Z_{X}-f_{X}\right)\left(Z_{Y}-f_{Y}\right)$, where for $\mathbf{1} X=\mathrm{Al}$ and $Y=\mathrm{C}$ and for $2 X=\mathrm{Ga}$ and $Y=\mathrm{C}$. Positions and relative intensities of peaks from contributing atom pairs are shown with vertical lines.

effect is, of course, enhanced by the electron-donating character of the tert-butyl groups. A similar difference is observed between the calculated (MP2/6-311+G*/WTBS) In-C distance in $\operatorname{In}\left(\mathrm{Bu}^{t}\right)_{3}$ $(2.247 \AA)$ and the values reported from the GED studies of $\mathrm{InMe}_{3}$ [2.16(4) $\AA^{34}$ and 2.093(6) $\AA^{35}$ ]. It is also expected that the $\mathrm{sp}^{3}$ hybridisation of the tert-butyl quaternary carbon would result in a longer $\mathrm{M}-\mathrm{C}$ distance than that observed for aryl derivatives in which the quaternary $\alpha$ carbon has $\mathrm{sp}^{2}$ hybridisation. This is indeed observed: $\mathrm{AlMes}_{3}\left(\mathrm{Mes}=2,4,6-\mathrm{Me}_{3} \mathrm{C}_{6} \mathrm{H}_{2}\right)$ [1.995(8) $\left.\AA^{36}\right], \mathrm{GaMes}_{3}$ [1.968(4) $\left.\AA^{37}\right], \mathrm{GaPh}_{3}\left[1.946(7)\right.$ to $\left.1.968(5) \AA^{38}\right], \mathrm{InPh}_{3}$ [2.11(1) to 2.15(1) $\AA^{38}$ ] $\operatorname{InMes}_{3}\left[2.163(5)\right.$ to 2.170(5) $\AA^{15}$ ]. However, what is rather unexpected is that the $\mathrm{M}-\mathrm{C}$ distances in $\mathrm{M}\left(\mathrm{Bu}^{t}\right)_{3}$ are close to those observed for their Lewis acid-base complexes, $\mathrm{M}\left(\mathrm{Bu}^{t}\right)_{3}(\mathrm{~L})$ : $1.98(1)$ to $2.07(2) \AA(\mathrm{Al})^{3,39}$ and $1.979(9)$ to $2.045(8) \AA(\mathrm{Ga}){ }^{40}$ The Lewis acid-base complexes would be expected to have longer $\mathrm{M}-\mathrm{C}$ distances based on (a) the increased coordination about the metal and (b) the $\mathrm{sp}^{3}$ hybridisation of a four-coordinate complex versus the $\mathrm{sp}^{2}$ hybridisation of the three-coordinate parent compounds.

Interestingly, both the shortest interligand $\mathrm{C} \cdots \mathrm{C}$ distances

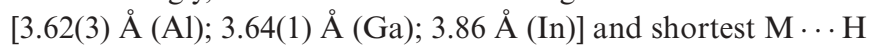


Table 2 Comparison of parameters from X-ray diffraction (XRD) with those from GED (for $\mathbf{1}$ and $\mathbf{2}$ ) or with those calculated $a b$ initio (for 3) ${ }^{a}$

\begin{tabular}{|c|c|c|c|c|c|c|}
\hline \multirow[b]{2}{*}{ Parameter } & \multicolumn{2}{|l|}{1} & \multicolumn{2}{|l|}{2} & \multicolumn{2}{|l|}{3} \\
\hline & XRD & GED & XRD & GED & XRD & $a b$ initio \\
\hline $\mathrm{M}-\mathrm{C}_{\mathrm{n}}$ & 2.006 & $2.008(2)$ & 2.007 & $2.032(2)$ & 2.222 & 2.238 \\
\hline $\mathrm{C}-\mathrm{C}_{\text {mean }}$ & 1.540 & $1.5470(6)$ & 1.49 & $1.5406(8)$ & 1.522 & 1.532 \\
\hline$\sum \mathrm{C}-\mathrm{M}-\mathrm{C}$ & 355.37 & 356.4 & 360.0 & 357.9 & 359.63 & 358.8 \\
\hline
\end{tabular}

${ }^{a}$ All distances in $\AA$ and angles in ${ }^{\circ}$. All X-ray diffraction results from ref. 10. Values in parentheses are the esds on the last digit. Note that no esds were quoted in the original literature for some parameters.

distances [2.78(4) $\AA(\mathrm{Al}) ; 2.87(10) \AA(\mathrm{Ga}) ; 3.03 \AA$ (In)] for each compound correlate well with the respective $\mathrm{M}-\mathrm{C}$ distances. This suggests that the geometries of $\mathrm{M}\left(\mathrm{Bu}^{t}\right)_{3}$ are defined by the interligand steric interactions.

\section{Comparison of gas-phase and crystal structures}

Table 2 compares some parameters from X-ray diffraction structures of 1-3 with equivalent values from either GED experiments or from $a b$ initio calculations. In the crystalline phase, the molecules are less symmetrical than in the gas phase and some are disordered, leading to many different parameter values. Here only the mean values have been quoted. In order to simplify comparisons we refer only to the crystal structures determined by Downs and Parsons et al.,$^{10}$ with very similar results being reported elsewhere. ${ }^{9,11,12}$

In all cases the average bond lengths reported for the crystal structures are shorter than those in the gas phase, with the difference being greatest for the gallium compound. Such effects may arise from packing forces present in the solid phase, from thermal motion of atoms, or from the differences between nuclear positions and centres of electron density. With the exception of $\mathbf{1}$, the $\mathrm{MC}_{3}$ fragments are nearer to (or exactly) planar than those determined from the GED experiments. This might also be an effect of interaction with neighbouring molecules.

\section{Why is $\operatorname{In}\left(\mathrm{Bu}^{t}\right)_{3}$ photosensitive, when $\mathrm{Al}\left(\mathrm{Bu}^{t}\right)_{3}$ and $\mathrm{Ga}\left(\mathrm{Bu}^{t}\right)_{3}$ are not?}

Some physical properties of the tri-tert-butyl derivatives of aluminium, ${ }^{13}$ gallium ${ }^{14}$ and indium ${ }^{15}$ are summarised in Table 3. Studies using mass spectrometry and osmometry indicate that all three compounds are monomeric in both the gas phase and in solution; however, while $\mathbf{1}$ and $\mathbf{2}$ are colourless liquids that are stable to visible light, $\mathbf{3}$ is a yellow solid that decomposes rapidly in sunlight. Bradley and co-workers reported that this photodecomposition results in the formation of indium metal. ${ }^{41}$

Table 3 Selected physical properties of $\mathrm{M}\left(\mathrm{Bu}^{t}\right)_{3}(\mathrm{M}=\mathrm{Al}, \mathrm{Ga}, \mathrm{In})$

\begin{tabular}{lllll}
\hline Compound & $\begin{array}{l}\text { Melting } \\
\text { point } /{ }^{\circ} \mathrm{C}\end{array}$ & $\begin{array}{l}\text { Boiling point } \\
(0.01 \text { Torr }) /{ }^{\circ} \mathrm{C}\end{array}$ & Colour & Photosensitivity \\
\hline $\mathbf{1}$ & -10 & 27 & colourless & low (days) \\
$\mathbf{2}$ & -10 & 35 & colourless & low (days) \\
$\mathbf{3}$ & $\mathrm{n} / \mathrm{a}$ & $30^{a}$ & yellow & high (minutes) \\
& & & \\
${ }^{a} \operatorname{In}\left(\mathrm{Bu}^{t}\right)_{3}$ sublimes at this temperature. & & \\
\hline
\end{tabular}

We have found that the reaction is radical in nature and occurs in the gas phase, solution, and the solid state, and that it is linked directly to the weak charge-transfer band at $334 \mathrm{~nm}$; this is a very broad feature, so the tail could be responsible for the yellow colour of the sample. ${ }^{42}$ There are several structural factors that could be associated with this charge-transfer band, including an agostic $\mathrm{C}-\mathrm{H} \cdots$ In interaction or an out-of-plane distortion of the alkyl substituents. It has previously been reported that an agostic interaction exists in $\mathrm{InMes}_{3},{ }^{43}$ while $\mathrm{In}\left[\mathrm{CH}\left(\mathrm{SiMe}_{3}\right)_{2}\right]_{3}{ }^{44}$ is reported to have an out-of-plane deformation of the indium atom. The large size of indium compared to aluminium and gallium may offer more potential for overlap of the unfilled In $\mathrm{p}_{\mathrm{z}}$ orbital and the filled $\mathrm{C}-\mathrm{H} \sigma$ bonding orbital (see Fig. 4).



Fig. 4 Possible interaction between empty In $\mathrm{p}_{z}$ orbital and $\mathrm{C}-\mathrm{H} \sigma$ bonding orbital.

Unfortunately, we have been unable to collect electrondiffraction data for $\operatorname{In}\left(\mathrm{Bu}^{t}\right)_{3}$. However, the agreement between the electron-diffraction and ab initio structures for $\mathrm{Al}\left(\mathrm{Bu}^{t}\right)_{3}$ and $\mathrm{Ga}\left(\mathrm{Bu}^{t}\right)_{3}$ lends support to the presumption that the theoretical structure of $\operatorname{In}\left(\mathrm{Bu}^{t}\right)_{3}$, calculated at a similar level, should represent well the structure that would be observed experimentally in the gas phase.

Based upon the experimental and calculated structures of $\mathrm{Al}\left(\mathrm{Bu}^{t}\right)_{3}$ and $\mathrm{Ga}\left(\mathrm{Bu}^{t}\right)_{3}$ and the calculated structure of $\operatorname{In}\left(\mathrm{Bu}^{t}\right)_{3}$, it appears that the shortest $\mathrm{M} \cdots \mathrm{H}$ distances in all three compounds are sufficiently long to preclude $\beta$-H agostic interactions. ${ }^{45}$ In fact calculations show that the overlap of the unfilled In $\mathrm{p}_{z}$ orbital and the filled $\mathrm{C}-\mathrm{H} \sigma$ bonding orbital in $\operatorname{In}\left(\mathrm{Bu}^{t}\right)_{3}$ is actually slightly less than the equivalent overlaps in $\mathrm{Al}\left(\mathrm{Bu}^{t}\right)_{3}$ and $\mathrm{Ga}\left(\mathrm{Bu}^{t}\right)_{3}$. Finally, the increased $\mathrm{C} \cdots \mathrm{C}$ interligand distances in $\operatorname{In}\left(\mathrm{Bu}^{t}\right)_{3}$ will allow for less restricted rotation of the tert-butyl ligands, further limiting the viability of an agostic interaction. Based upon these observations, we can conclude that the difference in photosensitivity of $\operatorname{In}\left(\mathrm{Bu}^{t}\right)_{3}$ compared to $\mathrm{Al}\left(\mathrm{Bu}^{t}\right)_{3}$ and $\mathrm{Ga}\left(\mathrm{Bu}^{t}\right)_{3}$ is not based on a structural difference.

Although there has been a reassessment of the exact values of M-C bond strengths for the Group 13 metals, ${ }^{46,47}$ it is commonly accepted that the bond strengths for the tri-alkyls follow the order $\mathrm{Al}>\mathrm{Ga}>\mathrm{In}{ }^{48-50}$ Thus, based on the bond-dissociation energy for the $\left(\mathrm{Bu}^{t}\right)_{2} \mathrm{M}-\mathrm{CMe}_{3}$ bond, it is expected that homolytic bond cleavage for indium would be more favourable than for aluminium or gallium. Although such a process would be expected to be thermolytic, Stuke and co-workers have shown that Group 13 trialkyls undergo photolytic decomposition at wavelengths below $260 \mathrm{~nm}^{51}$

In each of 1-3 the HOMO is a degenerate pair of $\mathrm{M}-\mathrm{C} \sigma$ orbitals and the LUMO is the metal $\mathrm{p}_{z}$ orbital, with the $\mathrm{M}-\mathrm{C}$ $\sigma^{*}$ orbitals only slightly higher in energy. It was hypothesised that the excitation of an electron from the In-C $\sigma$ bonding orbital to the In $p_{z}$ orbital could provide a suitable pathway to the homolytic bond cleavage observed under visible light irradiation. 
This charge transfer is formally forbidden on symmetry grounds but, as was mentioned earlier, the experimental peak was quite weak. Although CASSCF calculations show that the excitation energy to the LUMO is $4.11 \mathrm{eV}$ for 3 , corresponding to radiation with a wavelength of $302 \mathrm{~nm}$, they also predict that $\mathbf{1}$ and $\mathbf{2}$ will be excited by 248 and $267 \mathrm{~nm}$ light, respectively. Similar results were obtained from time-dependent DFT calculations. These showed that the wavelengths of light required to excite an electron from the ground state into a singlet excited state for 1-3 were 288, 291 and $333 \mathrm{~nm}$, respectively. The gap in energy between the ground state and first excited state is definitely smaller for the indium compound. However, the difference is not dramatic and it seems unlikely that the different photochemistry exhibited by 3 is electronic in nature, unless extension of the $333 \mathrm{~nm}$ band into the visible region is responsible. The $\mathrm{Ga}$ and $\mathrm{Al}$ compounds would absorb well into the UV region, which is also where Pyrex glass absorbs, which may account for the lack of decomposition of these compounds. As Group 13 tri-alkyls have been shown to dissociate under UV light ${ }^{51}$ it seems likely that all three $\mathrm{Bu}^{t}$ derivatives would also do so.

\section{Conclusions}

The molecular structures of $\mathrm{Al}\left(\mathrm{Bu}^{t}\right)_{3}$ and $\mathrm{Ga}\left(\mathrm{Bu}^{t}\right)_{3}$ have been determined by gas-phase electron diffraction and compared to the structures predicted $a b$ initio and to those obtained by X-ray diffraction. The calculated and gas-phase experimental structures show good agreement, which gives confidence in the prediction of the structure of the indium analogue, 3 . Based on the structures for $\mathrm{M}\left(\mathrm{Bu}^{t}\right)_{3}$ throughout the series $\mathrm{M}=\mathrm{Al}, \mathrm{Ga}$, In, it is clear that the photosensitivity of $\mathbf{3}$ is not associated with any structural artefacts such as agostic In $\cdots$ C or In $\cdots H$ interactions. Instead the evidence points to a charge-transfer process, with an electron being excited from an $\mathrm{M}-\mathrm{C} \sigma$ bonding orbital into the unoccupied metal $\mathrm{p}_{\mathrm{z}}$ orbital. Calculations show that this process occurs at a slightly longer wavelength for the indium compound than for the aluminium or gallium analogues. The tail of the very broad band observed experimentally for $\operatorname{In}\left(\mathrm{Bu}^{t}\right)_{3}$ could be the source of the yellow colouring of the sample. That no photodissociation is observed for $\mathrm{Al} / \mathrm{Ga}\left(\mathrm{Bu}^{t}\right)_{3}$ could result from absorption of UV light by their Pyrex glass containers.

There is evidence that these phenomena are not unique to $\mathrm{M}\left(\mathrm{Bu}^{t}\right)_{3}$. Although $\operatorname{In}\left(\mathrm{Pr}^{i}\right)_{3}$ is a clear liquid at room temperature with low photosensitivity, at temperatures close to its boiling point it takes on a yellow colour and exhibits photosensitivity similar to that of $\operatorname{In}\left(\mathrm{Bu}^{t}\right)_{3}{ }^{42}$ Given the reversibility of this effect, it is probable that at low temperatures $\operatorname{In}\left(\mathrm{Pr}^{i}\right)_{3}$ is an oligomer but becomes monomeric with increased temperature. It seems, therefore, that a monomeric structure is key to the photodecomposition and this is reinforced by the low photosensitivity of tetrameric $\mathrm{InMe}_{3}{ }^{42}$

\section{Acknowledgements}

The National Science Foundation is acknowledged for an International Travel Grant (Grant No. INT-9622206). Additional financial support for this work was provided by the EPSRC, who supported the Edinburgh GED Service (GR/K44411). DAW thanks Drs Andrew Turner and Paul Murray for useful discussions and the NSCCS for computational resources.

\section{References}

1 A. R. Barron, Chem. Soc. Rev., 1993, 93; A. R. Barron, Commun. Inorg. Chem., 1993, 14, 123; A. R. Barron, Macromol. Symp., 1995, 97, 15; A. R. Barron, Adv. Mater. Opt. Electron., 1995, 5, 245.

2 C. A. Tolman, Chem. Rev., 1977, 77, 313.

3 C. C. Landry, C. J. Harlan, S. G. Bott and A. R. Barron, Angew. Chem., Int. Ed. Engl., 1995, 34, 1201; C. N. McMahon, S. G. Bott and A. R. Barron, J. Chem. Soc., Dalton Trans., 1997, 3129.

4 J. A. Francis, C. N. McMahon, S. G. Bott and A. R. Barron, Organometallics, 1999, 18, 4399.

5 A. N. MacInnes, M. B. Power, A. F. Hepp and A. R. Barron, J. Organomet. Chem., 1993, 449, 95.

6 C. C. Landry, A. Haynes, A. R. Barron, I. Haiduc and C. Silvestru, Polyhedron, 1996, 15, 391; W. M. Cleaver, A. R. Barron, A. R. McGuffrey and S. G. Bott, Polyhedron, 1994, 13, 2831.

7 E. G. Gillan, S. G. Bott and A. R. Barron, Chem. Mater, 1997, 9, 796.

8 D. A. Fletcher, R. F. McMeeking and D. Parkin, Chemical Database Service at Daresbury Laboratory, J. Chem. Inf. Comput. Sci., 1996, 36, 746.

9 M. Woski and N. W. Mitzel, Z. Naturforsch., B: Chem. Sci., 2004, 59, 269.

10 A. R. Cowley, A. J. Downs, S. Marchant, V. A. Macrae, R. A. Taylor and S. Parsons, Organometallics, 2005, 24, 5702.

11 A. Kuczkowski, S. Schulz and M. Nieger, Appl. Organomet. Chem., 2004, 18, 244.

12 W. Uhl, C. H. Emden, G. Geiseler and K. Harms, Z. Anorg. Allg. Chem., 2003, 629, 2157.

13 W. Uhl, Z. Anorg. Allg. Chem., 1989, 570, 37; H. Lehmkuhl, O. Olbrysch and H. Nehl, Liebigs Ann. Chem., 1973, 708; H. Lehmkuhl and O. Olbrysch, Liebigs Ann. Chem., 1973, 715.

14 R. A. Kovar, H. Derr, D. Brandau and J. O. Callaway, Inorg. Chem., 1975, 14, 2809.

15 C. M. Huntley, G. S. Laurenson and D. W. H. Rankin, J. Chem. Soc., Dalton Trans., 1980, 954.

16 J. R. Lewis, P. T. Brain and D. W. H. Rankin, Spectrum, 1997, 15, 7.

17 S. L. Hinchley, H. E. Robertson, K. B. Borisenko, A. R. Turner, B. F. Johnston, D. W. H. Rankin, M. Ahmadian, J. N. Jones and A. H. Cowley, Dalton Trans., 2004, 2469.

18 A. W. Ross, M. Fink and R. Hilderbrandt, in International Tables for Crystallography, ed. A. J. C. Wilson, Kluwer Academic Publishers, Dordrecht, The Netherlands, 1992, vol. C, p. 245.

19 EPSRC National Service for Computational Chemistry Software. URL http://www.nsccs.ac.uk.

20 M. J. Frisch, G. W. Trucks, H. B. Schlegel, G. E. Scuseria, M. A. Robb, J. R. Cheeseman, J. A. Montgomery, Jr., T. Vreven, K. N. Kudin, J. C. Burant, J. M. Millam, S. S. Iyengar, J. Tomasi, V. Barone, B. Mennucci, M. Cossi, G. Scalmani, N. Rega, G. A. Petersson, H. Nakatsuji, M. Hada, M. Ehara, K. Toyota, R. Fukuda, J. Hasegawa, M. Ishida, T. Nakajima, Y. Honda, O. Kitao, H. Nakai, M. Klene, X. Li, J. E. Knox, H. P. Hratchian, J. B. Cross, C. Adamo, J. Jaramillo, R. Gomperts, R. E. Stratmann, O. Yazyev, A. J. Austin, R. Cammi, C. Pomelli, J. W. Ochterski, P. Y. Ayala, K. Morokuma, G. A. Voth, P. Salvador, J. J. Dannenberg, V. G. Zakrzewski, S. Dapprich, A. D. Daniels, M. C. Strain, O. Farkas, D. K. Malick, A. D. Rabuck, K. Raghavachari, J. B. Foresman, J. V. Ortiz, Q. Cui, A. G. Baboul, S. Clifford, J. Cioslowski, B. B. Stefanov, G. Liu, A. Liashenko, P. Piskorz, I. Komaromi, R. L. Martin, D. J. Fox, T. Keith, M. A. Al-Laham, C. Y. Peng, A. Nanayakkara, M. Challacombe, P. M. W. Gill, B. Johnson, W. Chen, M. W. Wong, C. Gonzalez and J. A. Pople, Gaussian 03, Revision C.01, Gaussian, Inc., Wallingford, CT, 2004.

21 J. S. Binkley, J. A. Pople and W. J. Hehre, J. Am. Chem. Soc., 1980, 102, 939; M. S. Gordon, J. S. Binkley, J. A. Pople, W. J. Pietro and W. J. Hehre, J. Am. Chem. Soc., 1982, 104, 2797; W. J. Pietro, M. M. Francl, W. J. Hehre, D. J. DeFrees, J. A. Pople and J. S. Binkley, J. Am. Chem. Soc., 1982, 104, 5039 .

22 W. J. Hehre, R. Ditchfield and J. A. Pople, J. Chem. Phys., 1972, 56, 2257; P. C. Hariharan and J. A. Pople, Theor. Chim. Acta, 1973, 28, 213; M. S. Gordon, Chem. Phys. Lett., 1980, 76, 163.

23 R. Krishnan, J. S. Binkley, R. Seeger and J. A. Pople, J. Chem. Phys., 1980, 72, 650; A. D. McLean and G. S. Chandler, J. Chem. Phys., 1980, 72, 5639 .

24 S. Huzinaga and M. Klobukowski, THEOCHEM, 1988, 167, 1. 
25 V. A. Sipachev, THEOCHEM, 1985, 121, 143; V. A. Sipachev, J. Mol. Struct., 2001, 567, 67.

26 D. Hegarty and M. A. Robb, Mol. Phys., 1979, 38, 1795; R. H. E. Eade and M. A. Robb, Chem. Phys. Lett., 1981, 83, 362; H. B. Schlegel and M. A. Robb, Chem. Phys. Lett., 1982, 93, 43; F. Bernardi, A. Bottini, J. J. W. McDougall, M. A. Robb and H. B. Schlegel, Far. Symp. Chem. Soc., 1984, 19, 137; N. Yamamoto, T. Vreven, M. A. Robb, M. J. Frisch and H. B. Schlegel, Chem. Phys. Lett., 1996, 250, 373; M. J. Frisch, I. N. Ragazos, M. A. Robb and H. B. Schlegel, Chem.Phys. Lett., 1992, 189, 524.

27 R. E. Stratmann, G. E. Scuseria and M. J. Frisch, J. Chem. Phys., 1998, 109, 8218; R. Bauernschmitt and R. Ahlrichs, Chem. Phys. Lett., 1996, 256, 454; M. E. Casida, C. Jamorski, K. C. Casida and D. R. Salahub, J. Chem. Phys., 1998, 108, 4439.

28 A. D. Becke, J. Chem. Phys., 1993, 98, 5648; C. Lee, W. Yang and R. G. Parr, Phys. Rev. B, 1992, 37, 785; B. Miehlich, A. Savin, H. Stoll and H. Preuss, Chem. Phys. Lett., 1989, 157, 200.

29 P. J. Hay and W. R. Wadt, J. Chem. Phys., 1985, 82, 270; W. R. Wadt and P. J. Hay, J. Chem. Phys., 1985, 82, 284; P. J. Hay and W. R. Wadt, J. Chem. Phys., 1985, 82, 299.

30 N. W. Mitzel and D. W. H. Rankin, Dalton Trans., 2003, 3650.

31 A. Almenningen, S. Halvorsen and A. Haaland, Acta Chem. Scand., 1971, 25, 1937.

32 B. Beagley, D. G. Schmidling and I. A. Steer, J. Mol. Struct., 1974, 21 , 437.

33 A. F. M. M. Rahman, K. F. Siddiqul and J. P. Oliver, Organometallics, 1982, 1,881.

34 L. Pauling and A. W. Laubengayer, J. Am. Chem. Soc., 1941, 63, 480.

35 G. Barbe, J. L. Hencher, Q. Shen and D. G. Tuck, Can. J. Chem., 1974, 52, 3936.
36 J. J. Jerius, J. M. Hahn, A. F. M. M. Rahman, O. Mols, W. H. Ilsey and J. P. Oliver, Organometallics, 1986, 5, 1812.

37 O. T. Beachley, Jr., M. R. Churchill, J. C. Pazik and J. W. Ziller, Organometallics, 1986, 5, 1817.

38 J. F. Malone and W. S. McDonald, J. Chem. Soc. A, 1970, 3363.

39 C. J. Harlan, S. G. Bott and A. R. Barron, J. Am. Chem. Soc., 1995, 117, 6465; C. N. McMahon and A. R. Barron, J. Chem. Crystallogr., 1997, 27, 171; C. L. Aitken and A. R. Barron, J. Chem. Crystallogr., 1999, 29, 993.

40 A. Keys, T. Barbarich, S. G. Bott and A. R. Barron, J. Chem. Soc., Dalton Trans., 2000, 577.

41 D. C. Bradley, D. M. Frigo, M. B. Hursthouse and B. Hussain, Organometallics, 1988, 7, 1112 .

42 W. M. Cleaver, PhD Thesis, Harvard University, 1994.

43 J. T. Leman and A. R. Barron, Organometallics, 1989, 8, 2214.

44 A. J. Carty, M. J. Gynane, M. F. Lappert, S. J. Miles, A. Singh and N. J. Taylor, Inorg. Chem., 1980, 19, 3637.

45 M. Brookhart and M. L. H. Green, J. Organomet. Chem., 1983, 250, 395.

46 A. H. McDaniel and M. D. Allendorf, Chem. Mater., 2000, 12, 450.

47 M. D. Allendorf, C. F. Melius and C. W. Bauschlicher, J. Phys. IV, 1999, 9, PR8-23.

48 D. K. Russell, Chem. Vap. Deposition, 1996, 2, 223.

49 M. G. Jacko and S. J. W. Price, Can. J. Chem., 1964, 42, 1198.

50 W. D. Clark and S. J. W. Price, Can. J. Chem., 1968, 46, 1633.

51 Y. Zhang, T. Beuermann and M. Stuke, Appl. Phys. B, 1989, 48, 97; Y. Zhang and M. Stuke, Chemtronics, 1988, 3, 230; W. M. Cleaver, A. R. Barron, Y. Zhang and M. Stuke, Appl. Surf. Sci., 1992, 54, 8; Y. Zhang, W. M. Cleaver, M. Stuke and A. R. Barron, Appl. Phys. A, 1992, 55, 261. 